\title{
Empyema: An increasing concern in Canada
}

\author{
Christian Finley MD MPH ${ }^{1}$, Joanne Clifton MSc ${ }^{1}$, J Mark FitzGerald MB MD FRCP FACCP ${ }^{2}$, John Yee MD FRCSC
}

\author{
C Finley, J Clifton, JM FitzGerald, J Yee. Empyema: \\ An increasing concern in Canada. Can Respir J \\ 2008;15(2):85-89.
}

BACKGROUND: Empyema is a suppurative infection of the pleural space. Without prompt treatment, it can result in significant hospital stays, more invasive treatments as it progresses, and substantial morbidity and mortality.

OBJECTIVES: The primary objective of the present study was to evaluate whether there has been an increasing incidence of empyema in Canada. A secondary objective was to investigate whether this increase disproportionately affects any age group.

METHODS: The Discharge Abstract Database of the Canadian Institute for Health Information was used to evaluate national empyema data.

RESULTS: There were 11,294 patients identified with empyema over the nine-year period of the present study, of whom $31 \%$ were women. The mean $( \pm$ SD) length of stay was stable throughout the study at $21.82 \pm 33.88$ days, and $63.4 \%$ were discharged home. The incidence rate ratio (IRR) was defined as the ratio of the incidence rate of medical empyema in 2003 divided by the incidence rate in 1995. Medical empyema increased significantly (IRR 1.30, 95\% CI 1.20 to $1.41 ; \mathrm{P}<0.001$ ), as did empyema of unknown cause (IRR 1.29, 95\% CI 1.08 to $1.54 ; \mathrm{P}=0.005)$, while surgical empyema did not appear to increase (IRR $1.17,95 \%$ CI 0.97 to 1.43 ; $\mathrm{P}=0.114$ ).

A Poisson regression showed an increase in the indirect agestandardized IRR during the study period (IRR 1.025, 95\% CI 1.018 to $1.032 ; \mathrm{P}<0.001)$. The IRR for patients younger than 19 years of age from 1995 to 2003 was 2.20 (95\% CI 1.56 to 3.10), while the IRR in patients older than 19 years was 1.23 (95\% CI 1.14 to 1.34 ).

CONCLUSIONS: The present study demonstrates the increasing rate of empyema in Canada and shows a change in pattern of disease. The disproportionate rate change in the pediatric population suggests a high-risk group that needs to be addressed. In the adult population, while cause is unknown, it is necessary to continually educate frontline physicians to confront both the increased burden of this disease, caused by an aging population, and the underlying increasing rate of empyema in Canada.

\section{L'empyème : Un problème croissant au Canada}

HISTORIQUE : L'empyème est une infection suppurative de l'espace pleural. Sans une intervention rapide, il peut occasionner des taux d'hospitalisation importants, des traitements plus invasifs à mesure que la maladie progresse et une morbidité et mortalité substantielles.

OBJECTIFS : Le principal objectif de la présente étude était de vérifier si l'empyème a augmenté au Canada. Le second objectif était de vérifier si ce problème affecte un groupe d'âge plus qu'un autre.

MÉTHODES : Les auteurs ont interrogé la base de données sur les congés des patients de l'Institut canadien d'information sur la santé pour analyser les données sur l'empyème à l'échelon national.

RÉSULTATS : L'empyème a été diagnostiqué chez 11294 patients au cours de la période de neuf ans couverte par la présente étude; $31 \%$ étaient des femmes. La durée moyenne ( \pm É.-T.) du séjour est demeurée stable tout au long de l'étude soit $21,82 \pm 33,88$ jours et $63,4 \%$ ont quitté pour retourner à la maison. Le taux d'incidence (TI) a été défini par l'incidence d'empyème médical en 2003, divisée par son incidence en 1995. L'empyème médical a significativement augmenté (TI 1,30, IC à $95 \%$ $1,20$ à $1,41, p<0,001)$, tout comme l'empyème de cause inconnue (TI 1,29, IC à $95 \% 1,08$ à 1,54, p = 0,005), tandis que l'empyème chirurgical n'a pas semblé augmenter (TI 1,17 , IC à $95 \% 0,97$ à 1,43 , $\mathrm{p}=0,114)$. Une analyse de régression de Poisson a révélé une augmentation du TI indirect standardisé selon l'âge durant la période de l'étude (TI 1,025, IC à 95 \% 1,018 à 1,032, p < 0,001). Le TI chez les patients de moins de 19 ans entre 1995 et 2003 a été de 2,20 (IC à $95 \%$ 1,56 à 3,10), tandis que chez les patients de plus de 19 ans il a été de 1,23 (IC à $95 \%$ $1,14$ à 1,34$)$.

CONCLUSIONS : La présente étude montre l'augmentation des taux d'empyème au Canada et une modification du mode de présentation de la maladie. Le taux disproportionné de changement dans la population pédiatrique donne à penser qu'il existe un groupe à risque élevé sur lequel il y a lieu de se pencher. Chez la population adulte, bien que la cause soit inconnue, il faut continuer de prodiguer un enseignement aux médecins de premiers recours pour mieux s'attaquer au fardeau croissant de cette maladie associée au vieillissement de la population et au taux de croissance sous-jacent de l'empyème au Canada.

Key Words: Empyema; Infection; Parapneumonic effusion; Pleural effusion

C mpyema is a suppurative infection of the pleural space. It Chas been divided into three phases on a continuous spectrum (1): the acute phase, which is primarily exudative, followed by the fibrinopurulent phase, and the chronic or organizing phase. As polymorphonuclear leukocytes increase in the fluid, and fibrin is deposited, the phases evolve from exudative to fibrinopurulent. The fibrin forms a thick peel, which eventually leads to a reduction in the hemithorax volume and possible erosion either into the tracheobronchial tree or through the chest wall (empyema necessitans). The clinical distinction and the best treatment for each of these phases are still being debated, but if untreated, this disease will progress to an entrapped lung with significant chronic infection (2). The burden of this disease is such that it can result in significant hospital stays, more invasive treatments as it progresses, and substantial morbidity and mortality $(3,4)$.

${ }^{1}$ Division of Thoracic Surgery, Department of Surgery; ${ }^{2}$ Division of Respiratory Medicine, Department of Medicine, University of British Columbia, Vancouver, British Columbia

Correspondence: Dr Christian Finley, Department of Surgery, 910 West 10th Avenue, Vancouver, British Columbia V5Z 4 E3.

Telephone 604-616-3239, e-mail christianfinley@shaw.ca 
With prompt treatment, the infected pleural space can be effectively treated with tube thoracostomy, fibrinolytics, videoassisted thoracoscopic surgery and other less invasive means (2). Delays in prompt and appropriate treatment subsequently result in more invasive interventions, leading to a prolonged stay and recovery in the hospital (4).

The creation of empyema can be divided into two distinct mechanisms. Empyema occurs most commonly after pneumonia, with direct spread of organisms into the pleural space. This occurs in approximately $1 \%$ to $5 \%$ of pneumonias $(5,6)$. The other mechanism occurs after surgery, most commonly of the thorax, esophagus, lung or heart.

In the United Kingdom, there have been a number of reports of increasing incidence of empyema in the pediatric age group $(7,8)$. In the United States, there have also been some regional concerns of increasing rates of pediatric empyema (9). However, no study has evaluated the national rates of empyema in either Canada or the United States, nor has there been an investigation into the changing incidence of empyema in the adult population.

The primary objective of the present study was to evaluate whether there has been an increasing incidence of empyema in Canada. A secondary objective was to investigate whether this increase disproportionately affects any particular age group.

\section{Data acquisition and variables}

\section{METHODS}

Data for the present study were acquired from the Discharge Abstract Database, which collects information on all hospital discharges across Canada. Data for all patients diagnosed with empyema coded in International Classification of Diseases ninth revision (ICD-9) as 510.9 and 510.0, as well as in the 10th revision (ICD-10) as J86.0 and J86.9, were obtained for the period between 1995 and 2003. Data from the provinces of British Columbia, Alberta, Saskatchewan, Ontario, New Brunswick, Newfoundland and Labrador, Prince Edward Island and Nova Scotia, as well as all the Territories, were included in the present study. However, data from Quebec and Manitoba were excluded: Quebec did not start consistently collecting this information until 2001 and did not use the same data elements as the rest of Canada, and Manitoba did not participate in the Canadian Institute for Health Information (CIHI) data collection until 2004. Records with serious or warning error flags were excluded by CIHI.

ICD-9 was phased into ICD-10 throughout Canada from 2001 to 2003. CIHI reported that there was good correlation between the two coding systems (10).

Variables included in the database are length of stay (LOS), age, sex, province of hospital, ICD-9 diagnostic code, principal Canadian Classification of Procedures (CCP) code, ICD-10 diagnostic code, principal Canadian Classification of Health Interventions (CCI) code, discharge disposition, admission date and discharge date. Age-specific populations for Canada were obtained from Statistics Canada (11).

The ICD-9 is the predecessor of the ICD-10. Both are diagnostic coding systems for diseases. CCP is a coding system under ICD-9 for procedures performed on a given patient. CCP corresponds to the newer CCI code, which exists under the ICD-10 system. The principal CCI and CCP codes distinguish the 'principal' intervention on the patient as that which is most responsible for their hospital stay.
The cause of the patients' empyema can be classified into one of three categories using the CCP and CCI codes: 'surgical empyema' - patients who received an operation that entered the thoracic cavity before their empyema; 'medical empyema' patients who did not have a thoracic operation and were presumed to have a medical cause for their empyema (most frequently pneumonia); and 'unknown cause of empyema' patients with an unknown CCP or CCI.

The site of disposition was categorized by $\mathrm{CIHI}$ as home without support, home with support, another acute care facility, continuing care, patient transferred to other types of facilities (including ambulatory care, palliative care facility or hospice, addiction treatment centre, jails, infants and children discharged or detained by social services) or unknown.

\section{Analysis}

Values and distributions of the data variables were examined to obtain epidemiological data on patients with empyema. Data were stratified and analyzed by cause of empyema. The crude incidence rates for each cause were examined by comparing the 1995 rates with the 2003 incidence rates using a $\chi^{2}$ test.

Subsequently, only the medical empyema rates were evaluated. The incidence was adjusted for the age distribution of Canada in 1995 using the indirect age-standardization method. To evaluate the trend with time, a Poisson distribution was assumed. A Poisson regression was performed to evaluate the primary end point, ie, whether there was a change in age-adjusted medical empyema incidence rate with time.

To examine the secondary end point of differential distribution of medical empyema by age, the age-specific incident rates at the beginning and end of the study were compared using a $\chi^{2}$ analysis. Then the incidence rate ratios (IRRs) and the CIs were compared between patients younger than 19 years of age and those older than 19 years of age. The IRR was defined as the ratio of the incidence rate of medical empyema in 2003 divided by the incidence rate in 1995 . The percentage change from 1995 to 2003 was plotted on a graph to better display the age-specific changes.

Statistical calculations were all two-tailed and performed using Stata v9.0 (Stata Corp, USA), with significance level at $\mathrm{P}<0.05$.

\section{RESULTS}

There were 11,294 patients over the nine-year period of the present study, of whom $31 \%$ were women. The LOS was stable throughout the study, with a mean $( \pm$ SD) of $21.82 \pm 33.88$ days and a median LOS of 14 days. Figure 1 shows the crude frequency per year of each cause of empyema in the study population.

The crude IRR for 1995 and 2003 for medical empyema increased significantly (IRR $1.30,95 \%$ CI 1.20 to 1.41 ; $\mathrm{P}<0.001$ ), as did empyema of unknown cause (IRR $1.29,95 \%$ CI 1.08 to $1.54 ; \mathrm{P}=0.005$ ), while surgical empyema did not appear to increase (IRR 1.17, 95\% CI 0.97 to $1.43 ; \mathrm{P}=0.114$ ). Figure 2 shows the site of disposition for all patients with empyema in the present study. The number of patients discharged home without support decreased slightly over the study period, while the number of patients discharged to another acute care hospital or home with support increased proportionally.

A Poisson regression showed an increase in the indirect age-standardized IRR for 1995 and 2003 for medical empyema 


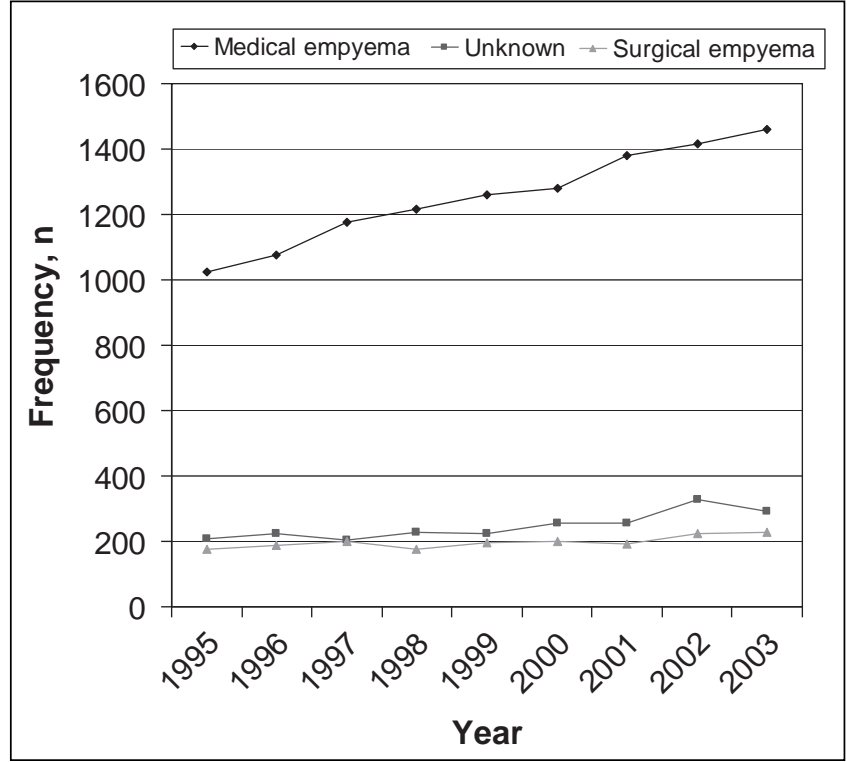

Figure 1) The crude frequency of empyema from 1995 to 2003 by cause of infection

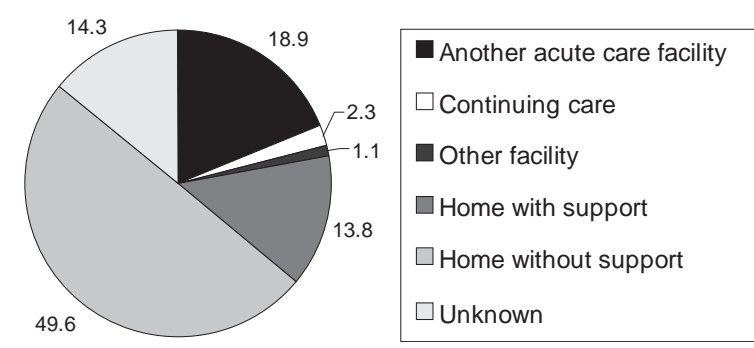

Figure 2) The disposition of all patients with empyema as a percentage of total discharges

of 1.025 (95\% CI 1.018 to $1.032 ; \mathrm{P}<0.001$ ). Figure 3 displays the percentage change in both crude total incidence rates and indirect age-standardized incidence rates from the 1995 baseline.

The age-specific incidence rate for medical empyema was plotted in Figure 4 for 1995 and 2003. There were four age ranges that showed significant changes: ages one to four years $(\mathrm{P}<0.001)$, five to nine years $(\mathrm{P}=0.004), 40$ to 44 years $(\mathrm{P}=0.016)$ and 50 to 54 years $(\mathrm{P}=0.007)$, while the other ranges did not reach statistical significance. Although the majority of the population had an increasing rate of empyema, the pediatric age groups were clearly affected disproportionally. The IRR for age group younger than 19 years for 1995 and 2003 was 2.20 (95\% CI 1.56 to 3.10), while in those older than 19 years, the IRR was 1.23 (95\% CI 1.14 to 1.34 ). The disproportionate change in age-specific incidence rates is best shown in Figure 5 as a percentage change from 1995 to 2003.

\section{DISCUSSION}

The incidence of empyema in Canada is increasing. It is known that very young or elderly people are more commonly afflicted with pneumonia (12). By examining the increasing rate of empyema with age in Figure 4, and knowing that the Canadian population is aging, we predict an increase in the number of cases of empyema in hospitals. This is represented in

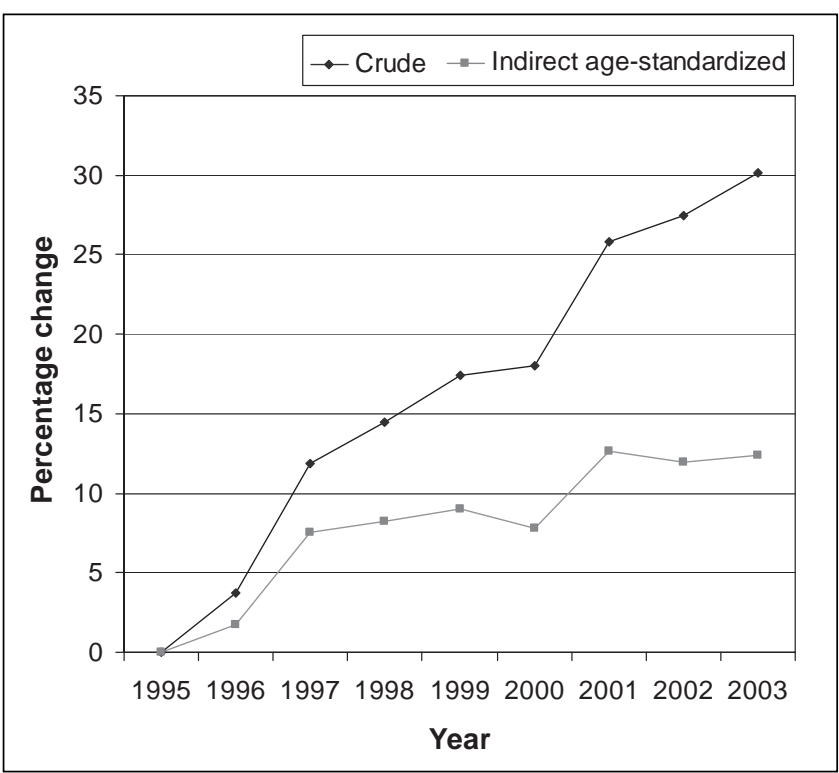

Figure 3) The percentage change in incidence rates from the 1995 baseline for the crude and indirect age-adjusted incidence rate

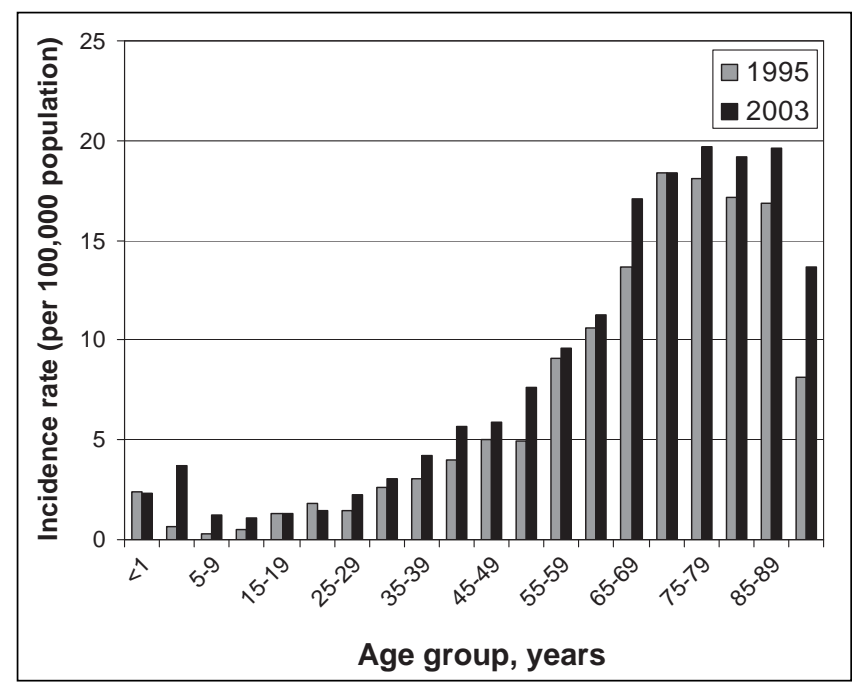

Figure 4) Comparison of age-specific incidence rates of medical empyema per 100,000 population in 1995 and 2003

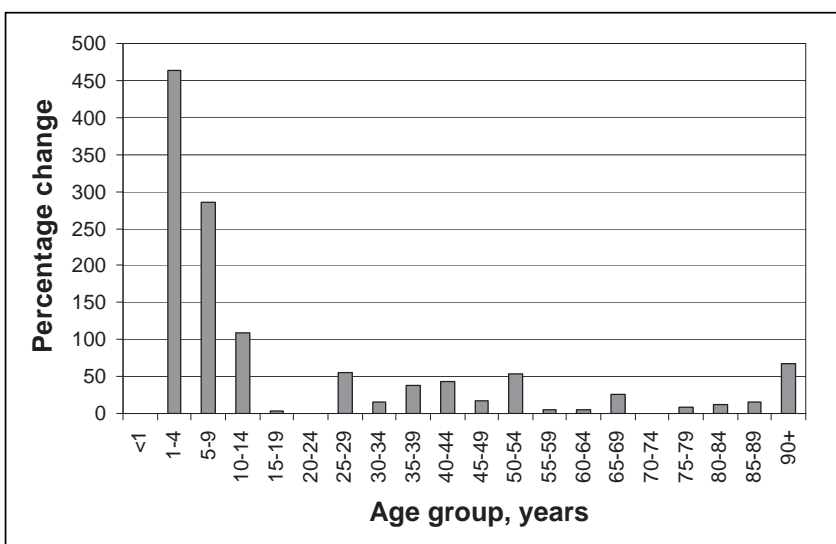

Figure 5) The percentage change from the 1995 baseline in the agespecific incidence rate in 2003 
Figure 3 by the crude incidence rate. It shows that the crude percentage increase in empyema was approximately $30 \%$ in 2003 - indirect age-standardization will control for this predictable change. Once the change in age was taken into account, represented by the indirect age-adjusted line in Figure 3, we can see that there was still a significant increase in empyema incidence rates (12.4\%) across Canada. Because significant length of hospital stays and resources are required to manage these patients, a huge increase in the burden of this disease occurred. Not only is the volume of cases occurring in hospitals affected by the aging population, but it is compounded by a changing disease pattern.

One distressing finding in the present study is the disproportionate rate of increase of empyema in children. In Figure 5, it is evident that the age group of one to four years had a $463 \%$ increase in empyema rates. Given the background of increasing overall rates, the increase in children was striking, which raises the question: Why are children more affected than adults?

When we examine the increase of empyema in children, we can hypothesize many possible causes, such as the increasing use of cross-sectional imaging, antibiotic resistance or less invasive management of parapneumonic effusions. The cause of this increasing incidence in children is unclear, but it likely relates to changing flora. Certainly the institution of vaccinations has changed the flora seen in pneumococcal infections in children $(13,14)$ and likely in adults. In Canada, children are immunized with a conjugated pneumococcal vaccination that covers eight serotypes. The most common cause of pediatric pneumococcal parapneumonic empyema is serotype 1 $(9,13,15)$, which is not covered by the conjugated pneumococcal vaccine. However, more than $90 \%$ of pneumococcal infections in children, including serotype 1 , are covered by the current 23-valent vaccine (16), which is currently only recommended for high-risk children.

Unfortunately, studies on the benefit of adult immunization are variable in their effect on the rates of community-acquired pneumonia $(16,17)$; hence, changing the immunization schedule may not offer the same benefit. Whether the effect in adults is due to the changing microbiological reservoir in children, increasing antibiotic resistance $(12,18)$ or possibly the increasing availability of CT scanners, which may be diagnosing previously unrecognized disease, is unclear. Empyema in adults, however, tends to result from different flora than in children (19). Another microbiological factor that can play a role in the creation of empyema is the organisms involved in the pneumonia.

It is intuitive that different organisms will generate different rates of empyemas. We know that Streptococcus pneumoniae causes the majority of community-acquired pneumonia, but only $2 \%$ to $5 \%$ of these result in empyemas (6), while agents like Staphylococcus aureus or Escherichia coli have much higher empyema rates (6) per infection.

This problem is compounded by the lack of aggressive treatment of parapneumonic effusions, and stresses the importance of education of front-line physicians in the treatment of early, complicated parapneumonic effusions and empyema. We know that patients who are not treated early and appropriately have a greater need for resources and poorer outcomes (2-4).

A limitation of the present study is the lack of a universal definition of empyema. It is difficult to define the phase of each empyema. In an administrative database, we simply have to accept the diagnosis of empyema and acknowledge the limitation. Coupled with this is the management of the empyema, which is not recorded accurately enough to comment on. Another concern with database analysis is the accuracy with which the data has been entered. CIHI had performed an analysis by reviewing charts and comparing them with the entered data (20). They found the expected transcription errors and discrepancies in interpretation, but concluded that overall the information was both reliable and reproducible. It is also important to acknowledge, as a limitation, the change in coding system that occurred near the end of the study period, which may have affected the results. However, all research into this transition by CIHI and the consistency of the data suggest a smooth transition.

\section{CONCLUSIONS}

Empyema is a serious medical condition that requires significant resources to manage and treat. Without prompt treatment, empyema results in increased morbidity and mortality. The present study demonstrates the increasing rate of incidence of empyema in Canada and shows a changing pattern of disease. The disproportionate rate change in the pediatric population identifies a high-risk group that needs to be addressed. More studies need to be conducted on causative factors, but high infection rates of serotypes not currently covered by immunization offer a possible solution. In the adult population, while cause is unknown, continued efforts to educate frontline physicians is necessary to confront the increased burden of disease caused by an aging population, and to address the underlying increasing rate of empyema in Canada.

\section{REFERENCES}

1. Andrews NC, Parker EF, Shaw RR, Wilson NJ, Webb WR. Management of nontuberculous empyema. Am Rev Respir Dis 1962;85:935-6.

2. Colice GL, Curtis A, Deslauriers J, et al. Medical and surgical treatment of parapneumonic effusions: An evidence-based guideline. Chest 2000;118:1158-71. (Erratum in 2001;119:319).

3. Bartlett JG, Gorbach SL, Thadepalli H, Finegold SM. Bacteriology of empyema. Lancet 1974;1:338-40.

4. Ashbaugh DG. Empyema thoracis. Factors influencing morbidity and mortality. Chest 1991;99:1162-5.

5. Ahmed RA, Marrie TJ, Huang JQ. Thoracic empyema in patients with community-acquired pneumonia. Am J Med 2006;119:877-83.

6. Shields T, Locicero J, Ponn R, Rusch V, eds. General Thoracic Surgery, 6th edn. Philadelphia: Lippincott Williams \& Wilkins, 2005:823.

7. Rees JH, Spencer DA, Parikh D, Weller P. Increase in incidence of childhood empyema in West Midlands, UK. Lancet 1997;349:402.

8. Playfor SD, Smyth AR, Stewart RJ. Increase in incidence of childhood empyema. Thorax 1997;52:932.

9. Byington CL, Spencer LY, Johnson TA, et al. An epidemiological investigation of a sustained high rate of pediatric parapneumonic empyema: Risk factors and microbiological associations. Clin Infect Dis 2002;34:434-40.

10. Canadian Institute for Health Information. Data quality of the Discharge Abstract Database following the first-year implementation of ICD-10-CA/CCI. Final report. Ottawa: Canadian Institute for Health Information, 2005.

11. Statistics Canada, CANSIM. Table 051-0001: Population by sex and age group, by province and territory. $<$ www40.statcan.ca/101/ cst01/demo31a.htm > (Version current at February 13, 2008).

12. Canadian Institute for Health Information, Canadian Lung Association, Health Canada, Statistics Canada. Respiratory Disease in Canada. Ottawa: Health Canada, 2001.

13. Byington CL, Korgenski K, Daly J, Ampofo K, Pavia A, Mason EO. Impact of the pneumococcal conjugate vaccine on 
pneumococcal parapneumonic empyema. Pediatr Infect Dis J 2006;25:250-4

14. Gonzalez BE, Hulten KG, Lamberth L, Kaplan SL, Mason EO Jr; the U.S. Pediatric Multicenter Pneumococcal Surveillance Group. Streptococcus pneumoniae serogroups 15 and 33: An increasing cause of pneumococcal infections in children in the United States after the introduction of the pneumococcal 7-valent conjugate vaccine. Pediatr Infect Dis J 2006;25:301-5.

15. Eastham KM, Freeman R, Kearns AM, et al. Clinical features, aetiology and outcome of empyema in children in the north east of England. Thorax 2004;59:522-5.

16. Jackson LA, Neuzil KM, Yu O, et al; Vaccine Safety Datalink. Effectiveness of pneumococcal polysaccharide vaccine in older adults. N Engl J Med 2003;348:1747-55.
17. Vila-Córcoles A, Ochoa-Gondar O, Hospital I, et al; EVAN Study Group. Protective effects of the 23-valent pneumococcal polysaccharide vaccine in the elderly population: The EVAN-65 study. Clin Infect Dis 2006;43:860-8.

18. Marshall DA, McGeer A, Gough J, et al. Impact of antibiotic administrative restrictions on trends in antibiotic resistance. Can J Public Health 2006;97:126-31.

19. Chen KY, Hsueh PR, Liaw YS, Yang PC, Luh KT. A 10-year experience with bacteriology of acute thoracic empyema: Emphasis on Klebsiella pneumoniae in patients with diabetes mellitus. Chest 2000;117:1685-9.

20. Richards J, Brown A, Homan C. Data Quality Study of the Canadian Discharge Abstract Database. Statistics Canada Symposium 2001 - Achieving data quality in a statistical agency: A methodological perspective. (Abst) 


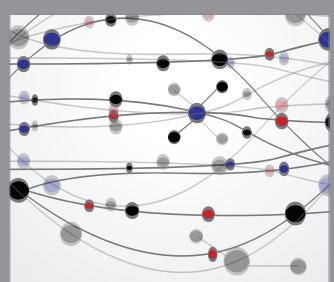

The Scientific World Journal
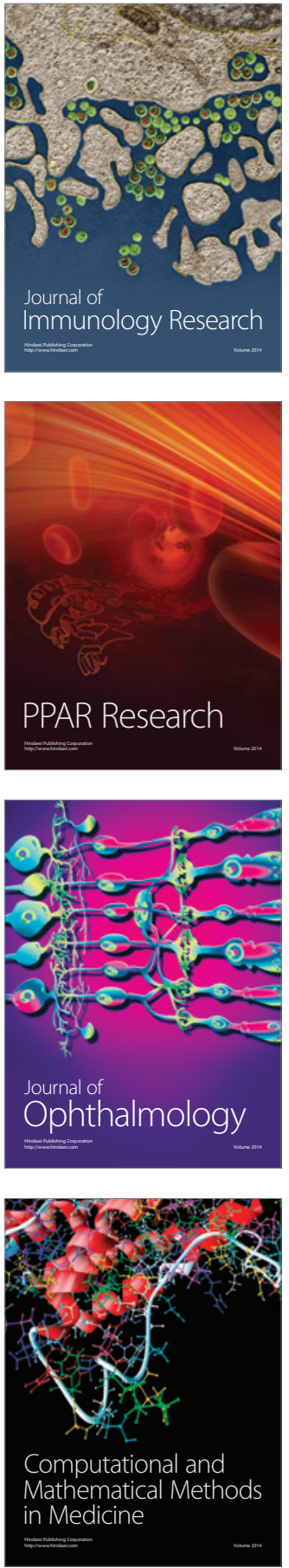

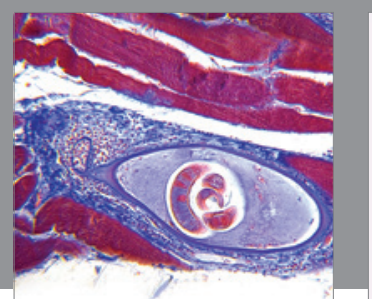

Gastroenterology Research and Practice

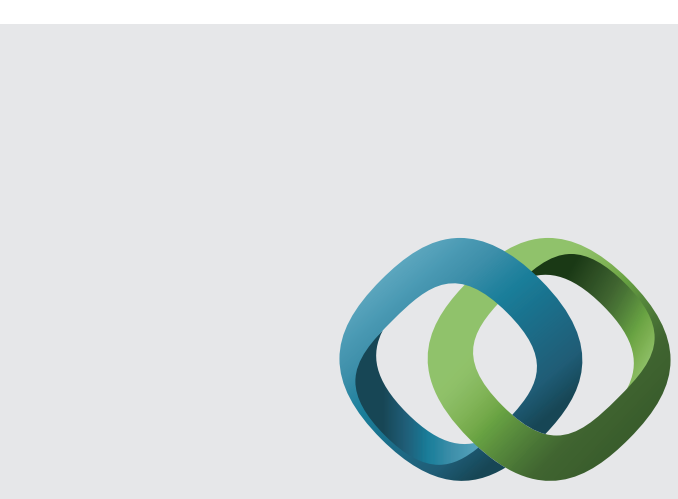

\section{Hindawi}

Submit your manuscripts at

http://www.hindawi.com
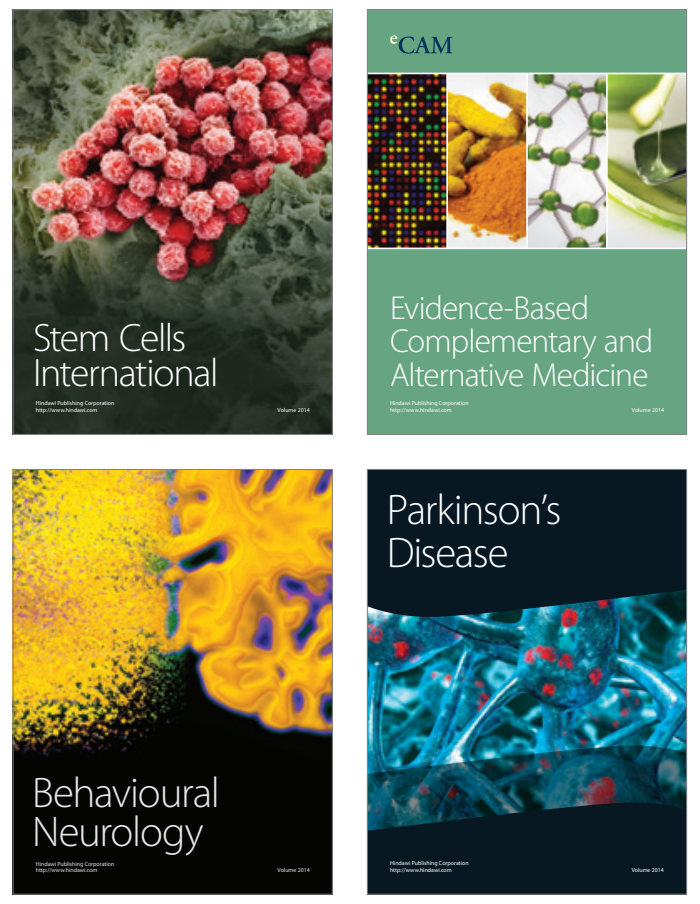
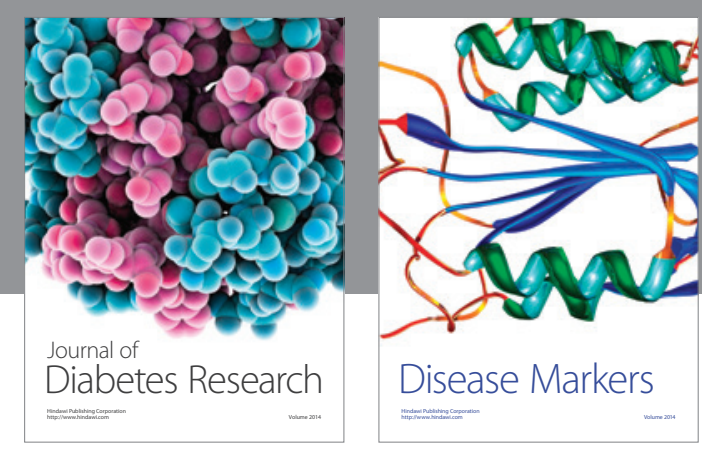

Disease Markers
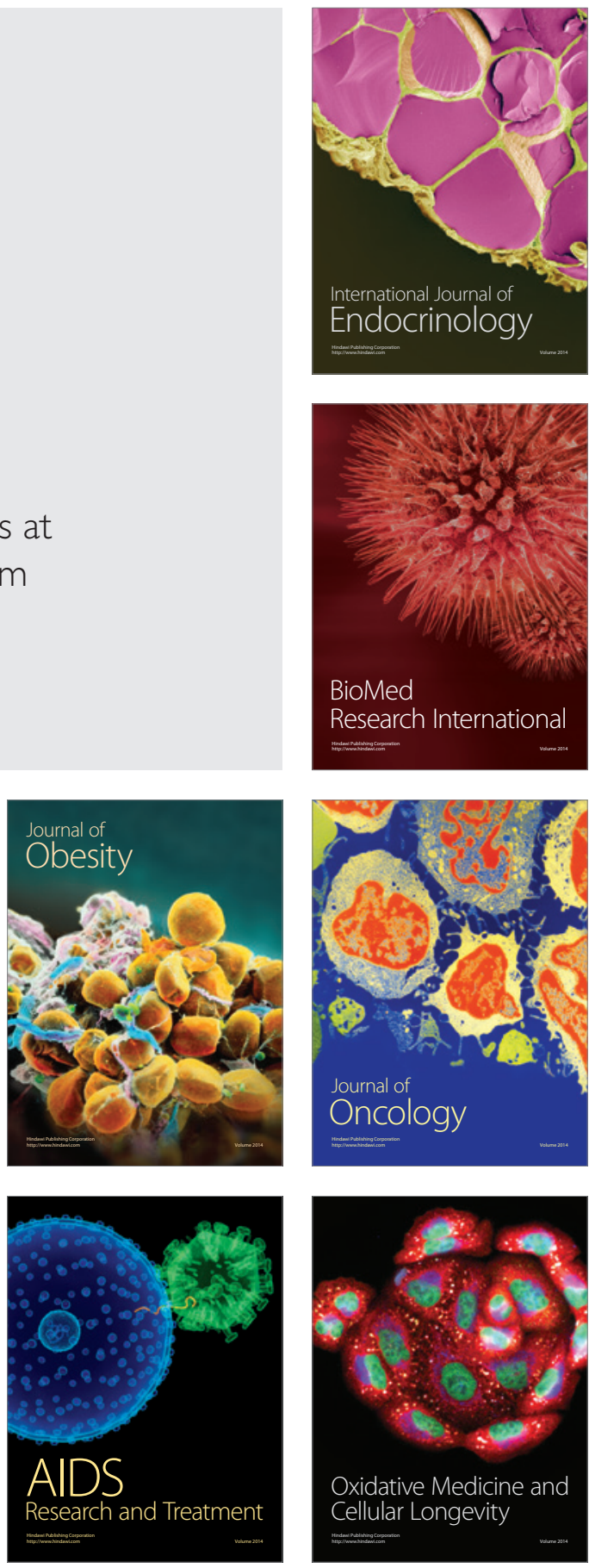